\title{
An Investigation into the Role of Extracurricular Activities in Supporting and Enhancing Students' Academic Performance in Tertiary Foundation Programs in Oman
}

\author{
Hranush Ginosyan \\ Sultan Qaboos University, Muscat, Oman \\ Victoria Tuzlukova \\ Sultan Qaboos University, Muscat, Oman \\ Fayaz Ahmed \\ Sultan Qaboos University, Muscat, Oman
}

\begin{abstract}
Sensing the pulse of globalization and the job market, the most recent trends in Oman' s tertiary education are about teaching methods and education practices' improvement. Recognizing the multidimensional and dynamic nature of the tertiary education learning environment, especially its foundation program cluster, and identified benefits of extra-curricular activities in having a positive impact on students, this paper reports on a study that examines the role of extracurricular activities as channels of support and foundation program students' academic performance enhancement. In more detail, using the example of the extracurricular activities offered by the Centre for Preparatory Studies at Sultan Qaboos University, it focuses on the student-perceived factors related to the value of participation in the extracurricular activities and subsequent effects on the tertiary foundation program students' development. The study employed a mixed study research design. The data was obtained from two instruments, namely student survey and student reflections which were then auto-analyzed using Google forms software. The findings revealed that extracurricular activities could provide a platform for new ways of learning, academic support, extra practice, variety and fun, and student skills' improvement. Specifically, they showed some improvement on the foundation program students' linguistic competences, critical thinking and time management skills. Also, involvement in structured extracurricular activities boosts students' self-confidence and self-esteem, and mitigates their transitional challenges.
\end{abstract}

Index Terms - extracurricular activities, academic performance, skills, tertiary foundation program students, Oman

\section{INTRODUCTION}

Extracurricular activities can present wide-ranging benefits for a language-centered institution. Extracurricular activities invite students to interact in natural environments outside of the reach of assessment, where they can achieve non-linguistic goals through the use of their target language. Language institutions should consider the ways these activities can supplement and enhance their own curricula.

Research on participation in extracurricular activities shows that participation is associated with more positive attitudes towards school (Davalos et al., 1999; Mahoney, 2000; Marsh 1992), better academic achievement (Eccles \& Barber, 1999; Silliker \& Quirk, 1997) and higher self-esteem and/or specific self-concepts (Holland \& Andre, 1987; Marsh, 1992; Zhang, 2001). Marsh (1992) argues that students' participation in extracurricular activities promoted by school can increase the school engagement, which leads to the development of more positive attitudes towards school and towards learning. Students participating in extracurricular activities exhibit more positive perceptions of school and lower probability of school dropout. This claim is supported by Mahoney and Cairns (1997) who argue that there is a negative correlation between the participation in extracurricular activities and school dropout. According to Davalos et al. (1999), by participating in extracurricular activities, students develop a sense of belonging that positively contributes to their own identity. What is more, participation in extracurricular activities can also increase academic achievement. According to Holland and Andre (1987), there is a positive relationship between participation in extracurricular activities and academic achievement. In a study with 10,944 students from 8th grade, Gerber (1996) demonstrates that participation in extracurricular activities leads to better school performance. Participation in extracurricular activities seems, also, to be positively related to self-esteem and/or self-concept. In a longitudinal study, Marsh (1992) claims that participation in extracurricular activities contributes to academic achievement and social self-concept. A 2010 study 
done by Tieu et al., has found out that the amount of structure present in out-of-class activities was positively related to university adjustment. Activity quality seems to arbitrate the relationship between the activity structure and university adjustment. More specifically, highly structured activities lead to more positive outcomes. Kitching \& Hulme (2013) put emphasis on the importance of embedding support for transition and opportunities for students to build relationships with each other and the faculty. Another important factor identified in research is youth and personal development. Involvement in structured extracurricular activities contributes to positive youth development (Larson, 2000; Eccles \& Gootman, 2002; Granger \& Kane, 2004).

Clearly, involvement in extracurricular activities can help students to develop peripheral attributes that are essential to classroom performance. The extent that these attributes can be developed can depend on the amount of emphasis an institution places on student engagement in extracurricular activities as well as the amount and types of activities that are offered by the institution. Much of the emphasis that students are exposed to comes directly from their teachers. As a part of a multi-level self-examination of their own institution's utilization of extracurricular activities, the authors of this study have researched students' perceptions of extracurricular activities offered at Sultan Qaboos University (SQU) in the Sultanate of Oman. Following the examination of teachers' views about extracurricular activities and their role as channels of support and foundation program students' academic performance enhancement, it explores the studentperceived factors related to the value of participation in extra-curricular activities offered by the Centre for Preparatory Studies (CPS) for its foundation program students and their effects on subsequent students' development.

\section{OVERVIEW: EXTRACURRICULAR ACTIVITIES AND THE FOUNDATION PROGRAM}

Recent studies on the most influential factors of students' adjustment to the context of tertiary and their academic performance, associated with an improved grade point average, higher educational aspirations, increased college attendance, and reduced absenteeism (Broh, 2002), indicate that extracurricular activities have become an important component of students' academic life (Seow \& Pan, 2014). To illustrate, CPS offers a unique platform known as ExtraCurricular Activities Centre (ECA) that has successfully supported its foundation program students over the years as a hub of creativity, innovation, and meaningful learning. The ECA is an informal and welcoming space that seeks to extend language learning beyond the four walls of the classroom with a wide array of highly engaging and immersive extracurricular activities conducted exclusively in English. Its primary objective is to bridge the gap between classroom learning and real-world needs by transforming skill-building into a stimulating and pleasurable experience for students.

SQU foundation program students are fresh graduates from high school who spend one or two semesters at CPS to achieve the core learning outcomes required to specialize in a subject of their choice. These students, uprooted from the cocoon of their home and family, experience a number of social, academic, and emotional hurdles as they try to adapt to a new learning environment. The ECA not only provides a non-threatening space where they can further build their language skills without any fear of being assessed, but also enable them to cope with a range of transitional challenges typical of university life. Also, in a predominantly exam-centered setting, what sets the ECA apart is the crucial role it plays in fostering active learning among students by motivating them to look beyond formal assessments and engage in a voluntary pursuit of learning as a goal in itself. The ECA meets three primary conditions required to promote active learning. It is non-coercive, so student participation in various activities is driven by volition and an intrinsic desire to learn. It is non-evaluative which offers a low-risk environment ideal for learning and experimentation. It is nonprescriptive and offers students a variety of activities to choose from, based on their own interests and preferred learning style. Its core objectives also align closely to the key outcomes of active learning which are learner autonomy and skill-formation. The ECA achieved a number of impressive milestones during the academic year 2019-20 when it hosted 21 weekly and bi-weekly extracurricular clubs in addition to a number of one-off workshops, presentations, competitions, and special events that attracted over 4000 participants in two semesters. It is important to examine how these activities engage and support CPS students by addressing different types of needs.

New students at university typically experience a range of affective needs, and their fulfilment is vital in easing them into a more challenging academic environment. Whereas extracurricular clubs such as Photography Club, Origami Club, Chess Club and Technology Club help students develop new hobbies and interests, Games Club and Film Club offer them purely recreational avenues for mitigating stress and anxiety. Another popular initiative is Culture Club that showcases countries as diverse as Belarus, Armenia, Colombia, Iran, Russia, South Korea, the United Kingdom, Romania, and the Caribbean Islands with each session focusing on a particular culture. These sessions use an engaging and lively format involving videos, games, quizzes, music and live demonstrations and go a long way in developing students' empathy and cross-cultural awareness. Another well-received initiative that helps promote this awareness is language workshop. The ECA organizes several language workshops each semester focusing on foreign as well as local Omani languages, such as Korean, Spanish, French, Balochi and Jabbali. These workshops involve introducing the basics of the target language in an interactive format with plenty of vocabulary games, pronunciation drills and handson activities offering students a rich and stimulating learning experience.

A positive attitude to life and learning is equally vital in coping with the transitional challenges at university. A new club called Mental Wellness Club was launched recently in collaboration with a guest expert to provide students with emotional and psychological support. In addition, the ECA regularly holds special motivational talks that feature distinguished speakers and eminent citizens sharing their success stories with students. The primary purpose of these 
talks is to build students' confidence and self-belief by highlighting the role of mental strength, discipline and positivity in achieving important life-goals. Participating in these activities not only ensures students' social and emotional wellbeing, but also lays the ground for a painless transition to university life.

A successful university education also requires meeting a variety of cognitive needs to develop the tools essential for future academic research and independent inquiry. The ECA clubs, such as Science News Club, Debate Club and Business Club go beyond providing simple infotainment and offer ample opportunities for sharpening a number of higher-order skills such as analysis, evaluation, problem-solving and critical thinking. Similarly, those with creative needs can join clubs such as Poetry Club, Art Club, Creative Writing Club and Music Club to explore and further develop their artistic talents and skills. The ECA remains the only known platform at SQU to host a variety of activities throughout the year to showcase and celebrate art and creativity, an often ignored but crucial aspect of university life.

Foundation program students spend 18 hours a week learning English which often proves insufficient for addressing all their immediate learning needs. Most students tend to be ill-equipped to cope with the demands of an intensive tertiary program in English and need further support and additional activities outside the classroom space to achieve the curricular outcomes. The ECA plays a crucial role in supporting these efforts with skill-focused clubs, such as Speaking Club, Reading Club, Listening Club and Spelling Club to supplement classroom learning.

A concerted effort has been made in recent years to engage more teacher volunteers resulting in a noticeable increase in the number CPS teachers actively involved in running and supporting various extracurricular initiatives. While teacher-led presentations and workshops are a major attraction for students, what lends the ECA its distinctive character is a team of committed and enthusiastic students who are responsible for planning, developing and presenting most of the clubs and activities. Some of these presenters are part of a core team of assistants who receive an hourly remuneration to perform a number of additional tasks ranging from organizing logistics for various special events to managing publicity and promotional initiatives. Working for the ECA is a truly empowering experience for these students as it opens up innumerable avenues for them to develop their inter-personal, organizational and leadership skills.

Education is viewed as a rather joyless, classroom-driven experience by students in most Omani tertiary institutions with little room for learning outside the conventional space. Extracurricular activities are often considered superficial, not integral to the language learning process. Some institutions do offer some sporadic opportunities for extracurricular activities, but they fail to rise above mere tokenism given the lack of sustained intensity and seriousness of approach. Most of these activities are teacher-centered with students' role mostly reduced to that of passive participants who have no say in planning or running them. In this context, the ECA's role in supporting the foundation program students at SQU assumes greater significance as it offers a unique template for success with its highly organized approach, active student involvement and consistent focus on holistic, independent learning. However, while recognizing general positive impact of extracurricular activities on foundation program students, it is still important to understand in more detail the role of extracurricular activities as channels of students' academic support within the foundation program cluster of the tertiary education learning environment in Oman.

\section{THE STUDY}

This study was initiated in January 2019 and completed in June 2020. Following the examination of teacherperceived role of extracurricular activities as channels of support and foundation program students' academic performance enhancement, it focused on the student-perceived factors related to the value of participation in extracurricular activities offered by CPS for its foundation program students and their effects on subsequent students' development.

\section{A. Methodology}

This is a second phase of a study built within the framework of mixed methods research design to obtain data on extracurricular activities' impact on student development using two main research instruments, namely student survey and student reflections which were then auto- analyzed using Google forms software.

In the first phase of the study, the study explored teacher perspectives on the potential benefits of increasing foundation program students' involvement in extracurricular activities with the aim to elicit common themes for the development of an online survey for students. This phase of the study involved unstructured and semi-structured interviews with 33 English language teachers who were involved in or facilitated extracurricular activities. Eight key perspectives or themes emerged from the interviews: language skills and academic performance, communicative and sociolinguistic competences, students' needs or interests, students' self-esteem and self-confidence, motivation or positive attitude towards learning, foundation program curriculum, culture and transitional challenges (Ginosyan, Tuzlukova, \& Hendrix, 2019).

In the second phase of the study, an online survey was developed based on the themes mentioned above. The survey consisted of three parts: background information (three questions), e.g. gender, age, English language proficiency level; perceptions of involvement in extracurricular activities (12 closed-ended questions), e.g. Do you think your involvement in the ECA helps you to adapt to the university life and cope with its challenges more successfully? Do you think your participation in ECA enables you to use English and express your ideas more confidently? Do you think ECA offers you 
opportunities to develop important study skills, such as critical thinking, problem solving and time-management? and attitudes to extracurricular activities (four open-ended questions), e.g. What do you like the most about ECA clubs \& activities? What is your favorite ECA? How often do you attend it? Why? The questions were translated into Arabic to prevent measurement errors that tend to occur when respondents cannot comprehend the questions as intended and ensure they have solicited truthful responses.

The respondents were asked to complete the survey after participating in an extracurricular activity facilitated by teachers and former students. The responses to questions were grouped and summarized. The open-ended responses were compared against the closed-ended ones.

The survey was administered after each extracurricular activity or event. The participants were invited to complete the survey after they have attended or participated in an extracurricular activity. The participants were informed that their responses would be used for research purposes and would not affect their grades. They could also choose to withdraw from the study at any point.

Student reflections were part of the portfolio component of the foundation program English language courses. Students were asked to reflect on an extracurricular activity or event they attended and share their experiences with teachers.

\section{B. Participants}

The study involved the tertiary foundation program's students taking courses in the areas of the English language, information technology and math's offered by CPS at SQU. The research participants were 529 students (288 males and 240 females). The English proficiency level of the participants ranged from the beginner to high intermediate; however, the majority of the participants (315-59.7\%) were from foundation program higher level English courses.

\section{Results and Discussion}

The first question looked into the relationship between students' involvement in extracurricular activities and their adaptation to university life. Most of the respondents $338(64 \%)$ believed that their involvement in extracurricular activities helps them adapt to university life and cope with its challenges more efficiently. This finding is in line with Tieu et al. (2010) who claim the amount of structure present in out-of-class activities was positively related to university adjustment. Only a small number of respondents found no relationship between 29 (5.5\%) students' involvement in the extracurricular activities and adaptation to university life and transitional challenges. About one third 161 (30.5\%) were neutral about the positive effects of students' involvement in extracurricular activities on transitional challenges.

The open-ended responses further confirm that involvement in extracurricular activities help them integrate. They reported engaging in extracurricular activities to socialize, interact, share and cooperate, relieve stress and make friends. Among common comments were "help me integrate and try to deal with males", "the ability to talk and many friends", "participate in groups", "teamwork and continuous participation in various occasions", "meeting new friends". This finding is in line with Kitching and Hulme (2013) who highlight the importance of providing support for transition and opportunities for students to build relationships with each other.

An interesting observation is that a good number $351(66.5 \%)$ of the respondents were of the opinion that participation in extracurricular activities makes university life more fun and less stressful, while 35 (6.6\%) of them disagreed with this point of view. A quarter 142 (26.9\%) of the respondents believed that engagement in extracurricular activities sometimes lessens stress of university life and makes it fun. Thus, it can be assumed that students' participation in extracurricular activities helps them enjoy university life and relieves stress caused by transitional challenges. Among the many common reasons mentioned about attending extracurricular activities were "to pass the time and have fun", "the ability to talk and making many friends", "depart from the study environment and daily routine", "integrate and try to deal with males", "getting out of school stresses", "honestly a lot of fun activities and contribute to spending fun time and the activities are performed excellently with others".

The next set of question was whether extracurricular activities provide students with enough opportunities to improve their overall English language skills as well as specific language skills. Many of the respondents 342 (64.8\%) found a strong relationship between extracurricular activities and opportunities to improve overall English language skills, with only $26(4.9 \%)$ claiming that students' involvement in extracurricular activities does not necessarily lead to improvement of overall English language skills. These findings corroborate many of the students' reflections and participants' responses to the open-ended survey question about their favorite extracurricular activities and clubs. The responses indicate that students' participation in extracurricular activities helps them practice and improve their English skills. Participants singled out "the ability to talk", "practice speaking with my teacher and friend", "using the language", "practice", "improve our skills", "improve our language", "learn new vocabulary", etc. About one third 160 $(30.3 \%)$ of the respondents had divided opinions about enhancement of overall English skills and the opportunities provided by extracurricular activities.

It is noteworthy that a vast majority of the respondents $370(70.1 \%)$ acknowledged that their participation in extracurricular activities and events has improved their speaking skills, while only a small number of those surveyed $131(24.8 \%)$ were indecisive about the effects of extracurricular activities involvement and improvement of speaking skills. The most popular ECA club identified by the respondents was the Speaking Club followed by the Debate Club. Frequent attendees engage in the club activities on average three to four times a semester. Their comments said: 
"Speaking clup (3 times)", "Speaking, when I get a free time, I have a lot of fun when doing this.", "Speaking in tutorial center and I attend in it about 7 time I attend to it because I want to improve my English", "Speaking club because I think that will help me to Speak", "debate club. not once", "The debate on a topic and the number of times 3 because it is fun and develops the social aspect, especially when raising a specific issue".

As for improvement of English vocabulary, 339 (64.2\%) of the respondents agreed that their engagement in extracurricular activities helped them improve their vocabulary, while only 20 (3.8\%) disagreed with this viewpoint. This could account for the fact that all extracurricular activities at CPS are conducted in English and encompass a wide variety of topics and interests. The respondents' comments were as follows: "vocabulary, I attended more than 2 times", "memorize words / infinite times / final case", etc.

There was a question about students' participation in extracurricular activities and practicing English outside the classroom. The majority of the respondents 339 (64.2\%) acknowledged that their participation in extracurricular activities encourages them to practice English more frequently outside the classroom, with only 48 (9.1\%) respondents disagreeing with this opinion. The remaining $26.9 \%$ were indecisive about this claim. According to some shared comments, the most popular extracurricular activities and clubs are those that target English skills. Students tend to attend these clubs and events to practice English and improve their English skills. They commented: "The activities that the student is offered to perform outside the study environment", "the ability to talk", "practice speaking with my teacher and friend", "using the language", "practice", "Speaking in tutorial center and I attend in it about 7 time I attend to it because I want to improve my English", "Speaking club because I think that will help me to Speak", "Memorize words / infinite times / final case", "Writing club to improve my writing skills", "Watching movies 4 times helps in acquiring some English vocabulary", etc.

Another set of questions addressed students' involvement in extracurricular activities and the impact on their classroom performance and coursework. Many respondents 306 (57.9\%) agreed that their classroom performance has been positively impacted by their involvement in extracurricular activities, with 39 (7.4\%) of the respondents not sharing this belief. The remaining one third 183 (34.7\%) were not sure whether their classroom performance has been affected by their involvement in extracurricular activities. This claim corroborates the assertion that participation in extracurricular activities contributes to academic achievement and social self-concept put forward by Marsh's (1992) and Cooper et al. (1999). The finding also substantiates the claim made by Silliker \& Quirk (1997) and Eccles \& Barber (1999) that students' engagement in extracurricular activities leads to higher academic performance.

According to $249(47.1 \%)$ of the respondents, extracurricular activities help them with the tasks they are required to perform on the course. A similar percentage (39.8\%) claimed that extracurricular activities sometimes help them with the coursework. This clearly indicates that students attend extracurricular activities to complete certain tasks required by the course. Their reflections and survey comments confirm that involvement in extracurricular activities helps with coursework: "improve my english, and to do my home work", "using onther articles to do our work". It is worth mentioning that despite the obvious benefits of extracurricular activities; only $13.1 \%$ of the respondents tend to get engaged in extracurricular activities due to intrinsic motivation. This indicates that students most probably attend the sessions because their teachers highly recommend them.

The results of the survey revealed divided opinions about the relevance of engagement in extracurricular activities and students' coursework. Some respondents 217 (41.1\%) found extracurricular activities relevant to their coursework, while $238(45.1 \%)$ were uncertain about the relevance of extracurricular activities to their course requirements. Surprisingly, only $73(13.1 \%)$ of the respondents participate in extracurricular activities regardless of their course requirements which means that these students are intrinsically motivated. This claim corroborates the previous findings that almost half of the respondents participate in extracurricular activities to meet the course requirements. Furthermore, their comments and reflections confirm that they attend extracurricular activities which are relevant to their coursework: "improve my english, and to do my home work", "using onther articles to do our work".

Extracurricular activities impact not only on linguistics skills and academic performance, but also other important skills and competencies, such as critical thinking, problem solving \& time-management and their extracurricular activities involvement. The survey responses revealed a strong relationship between students' development of critical thinking, problem solving \& time-management and their involvement in extracurricular activities. Many of the respondents surveyed $335(63.5 \%)$ noted that they improved their critical thinking, problem solving and timemanagement skills, with only $45(8.5 \%)$ finding no relationships between improvement of study skills and engagement in extracurricular activities. In the open-ended section of the survey, the respondents identified presentation skills, critical thinking, time management and taking responsibility as the skills gained from extracurricular activities. Their comments said, "Regulation activity. I attended 8 times. You can feel responsibility", "presentation activities", etc.

A good number $352(66.7 \%)$ of the respondents were convinced that their involvement in the extracurricular activities and events helps them to develop any useful skills that would be beneficial in the future. This could be further supported by the fact that only 24 (4.5\%) find extracurricular activities clubs and events beneficial for their future. This clearly indicates that students can gain skills that would be useful in the future. In particular, these skills contribute to personal development. This finding is in line with the claim in previous research that positive youth development is associated with students' involvement in structured extracurricular activities (Larson, 2000; Eccles \& Gootman, 2002; Granger \& Kane, 2004). The respondents mentioned in their reflections and open-ended part of the survey that the 
activities are "useful and enjoyable at the same time", they "spend quality time", "benefit from activities", and "learn from them", "build character and develop skills", "developing the student with all kinds of scientific aspects", "they are good and it could educate a person in some ways", to name but a few. "I am unable to attend the poetry club because $i$ have class in that time intrval but i might be able to next semester. ( $\mathrm{i}$ hope so). Why? Well, why not! It's enjoyable and i learn lots of new terms, techniques and types of poems and story writing. My dream is to become a successful fiction novelist and this club helps me a lot in improving my skills. It keeps me going on, like, i write everyday, at least 2500 words. So, i hope the creative writing club doesnt gets disbanded. I really depend on it.", one noteworthy comment said. This clearly shows that the respondent is gaining skills that will be beneficial in the future.

The analysis of the responses revealed a direct relationship between students' engagement in extracurricular activities and their ability to use English and express ideas more confidently. Many students 337 (63.8\%) who engage in extracurricular activities use English and express their ideas more confidently. Only 43 (8.1\%) out of 529 respondents disagreed with this claim. This can be attributed to the fact that most extracurricular activities are conducted in English and students need to use English if they wish to participate. The respondents' comments corroborate this finding. According to the shared comments, the respondents gained personal development and confidence building by participating in extracurricular activities. They said: "build character and develop skills", "developing the student with all kinds of scientific aspects", "they are good and it could educate a person in some ways", "it builds up confidence", "strengthening his self-confidence", "community development and voice ... to gain confidence greatly".

Overall, student reflections were in line with the survey results. Most students acknowledged the support provided by the writing and tutorial centers. Many students chose to attend Creative Writing and Story Telling events because they learnt about different elements of a story. Another popular club was the photography club which had regular attendees. This openly shows that extracurricular activities bring together people with similar interests and help them engage in their favorite activity after their classes. The Movie Club concluded the list of the popular clubs which brought together students who wanted to improve their English and have fun with their friends. Undoubtedly, extracurricular activities benefit students in various ways and many students view them as channels of support at different levels.

\section{CONCLUSION}

Extracurricular activities have a wide range of benefits for a language-centered institution. Extracurricular activities encourage students to interact in natural environments outside the classroom, where they can achieve non-linguistic goals through the use of their target language in a non-threatening way. The results of the study demonstrate that extracurricular activities provide students with ample opportunities to improve their overall English language skills and linguistic competencies. In particular, they enhance students speaking, writing, reading and presentation skills. Apart from linguistic competences, extracurricular activities promote students' critical thinking, time management and personal development. Involvement in structured extracurricular activities positively impacts on academic performance and boosts students' self-confidence and self-esteem. Last but not least, engagement in extracurricular activities helps foundation year students overcome challenges they face when adjusting to the new academic context. Hence, educational institutions should consider an array of ways extracurricular activities can supplement and enhance their own curricula, by offering a wide range of clubs, activities and events to meet students' academic needs and nonacademic interests, increasing the number of hands-on activities to get students engaged throughout the extracurricular activities' sessions and enhancing students' awareness of the benefits of extracurricular activities.

Based on the findings, extracurricular activities are recommended in all foundation program contexts across higher education institutions in Oman as a means for mitigating foundation students' transitional challenges and effectively supporting their academic development.

\section{ACKNOWLEDGMENTS}

The authors would like to extend their sincere appreciation and gratitude to the Deanship of Research at SQU for supporting this study by an internal research grant.

\section{REFERENCES}

[1] Broh, B. A. (2002). Linking extracurricular programming to academic achievement: Who benefits and why? Sociology of Education, 75, 69-96.

[2] Davalos, D.B., Chavez, E.L., \& Guardiola, R.J. (1999). The effects of extracurricular activity, ethnic identification, and perception of school on student dropout rates. Hispanic Journal of Behavioral Sciences, 21, 61-77.

[3] Eccles, J.S. \& Barber, B.L. (1999). Student Council, volunteering, basketball, or marching band: What kind of extracurricular involvement matters? Journal of Adolescent Research, 14, 10-43.

[4] Eccles, J.S. \& Gootman, J.A. (2002). Features of positive developmental settings. In: Eccles J.S., Gootman J.A., (Eds.). Community programs to promote youth development. (pp. 86-118). Washington, DC: National Academy Press.

[5] Gerber, S. (1996). Extracurricular activities and academic achievement. Journal of Research and Development in Education, 30(1), 42-50.

[6] Ginosyan, H., Tuzlukova, V. \& Hendrix, T. (2019). Teachers' perspectives on extra-curricular activities to enhance foundation program language learners' academic and social performances. Journal of Applied Studies in Language, 3(2), 168-177, 
Retrieved January23, 2020, from http://ojs.pnb.ac.id/index.php/JASL.

[7] Granger, R. C. \& Kane, T. (2004). Improving the quality of after-school programs. Education Week. 23, 76-77.

[8] Holland, A. \& Andre, T. (1987). Participation in extracurricular activities in secondary school: What is known, what needs to be known? Review of Educational Research, 57(4), 437- 466. Retrieved May 15, 2020 from https://doi.org/10.2307/1170431.

[9] Kitching, H. J. \& Hulme, J. (2013). Bridging the gap: facilitating students' transition from pre-tertiary to university psychology education. Psychology Teaching Review, 19 (2), 15-30.

[10] Larson, R. (2000). Toward a psychology of positive youth development. American Psychologist. 55, 170-183.

[11] Mahoney, J. (2000, March/April). School extracurricular activity participation as a moderator in the development of antisocial patterns. Child Development, 71(2), 502-516.

[12] Mahoney, J.L. \& Cairns, R.B. (1997). Do extracurricular activities protect against early school dropout? Developmental Psychology, 33,241-253.

[13] Marsh, H. (1992). Extracurricular activities: Beneficial extension of the traditional curriculum or subversion of academic goals? Journal of Educational Psychology, 84,553-562.

[14] Seow, P. S. \& Pan, G. Sh. S. (2014). A Literature review of the impact of extracurricular activities participation on students' academic performance. Journal of Education for Business. 89, (7), 361-366. Retrieved May 12, 2020, from http://ink.library.smu.edu.sg/soa_research/1250.

[15] Silliker, S. \& Quirk, J. (1997). The effect of extracurricular activity participation on the academic performance of male and female high students. The School Counselor, 44, 288-293.

[16] Tieu, T., Pancer, S., Pratt, M., Wintre, M., Birnie-Lefcovitch, S., Polivy, J., \& Adams, G. (2010). Helping out or hanging out: The features of involvement and how it relates to university adjustment. Higher Education, 60(3), 343-355. Retrieved July 3 , 2020, from www.jstor.org/stable/40783998.

[17] Zhang, L. (2001). Thinking styles, self-esteem, and extracurricular experiences. International Journal of Psychology, 36, 100107.

Hranush Ginosyan has an MA TEFL from the American University of Armenia. She is currently Assistant Lecturer at the Center for Preparatory Studies, Sultan Qaboos University, Oman where she teaches English and heads the Curriculum Committee of the Department of English for Sciences. Her research interests include learning styles and strategies, online learning, instructional design and transitional challenges. Hranush is an author of a number of publications and a presenter at international ELT conferences.

Victoria Tuzlukova obtained her PhD in Applied Linguistics from Pyatigorsk University of Foreign Languages in Russia. She has also held a PhD in Comparative Linguistics from Moscow State University since 2002. She has over 30 years teaching and research experience in Russia and Oman. Currently she is on the faculty at the Centre for Preparatory Studies of Sultan Qaboos University in Oman, which she joined in 2006. During her time at the Centre she has been involved in a number of research projects and initiatives. Her research interests focus on sociolinguistics, intercultural communication, foreign language acquisition and the role of culture in foreign language teaching and learning. Dr. Victoria Tuzlukova has presented and published in a broad variety of international conferences and journals.

Fayaz Ahmed teaches English at Sultan Qaboos University in Muscat, Oman. Mr. Ahmed has taught both EFL and EAP at a number of leading public universities in India and the Middle East over the past nineteen years. He holds an MA in English in addition to Cambridge DELTA and CELTA qualifications. He is also working with Bell International, UK as a DELTA trainer and the British Council as an IELTS examiner for speaking. His research interests include, but not limited to language assessment, SLA, learner motivation and writing center discourse. 